\title{
The Effectiveness of Using Online Blogging for Students' Individual and Group Writing
}

\author{
Hashem A. Alsamadani ${ }^{1}$ \\ ${ }^{1}$ Umm Al-Qura University, Makkah, Saudi Arabia \\ Correspondence: Hashem A. Alsamadani, Umm Al-Qura University, Makkah, Saudi Arabia. E-mail: \\ hmazawid@gmail.com
}

Received: August 13, 2017

Accepted: September 14, 2017

Online Published: December 22, 2017

doi:10.5539/ies.v11n1p44

URL: https://doi.org/10.5539/ies.v11n1p44

\begin{abstract}
The current research study investigates the effectiveness of online blogging for students' individual and group writing skills. The participants were divided into individual learners and group learners. They produced pre-writing and post-writing samples through blogging practices. The study conducted lasted for 14 weeks so that blogging could be optimized. The results of the study reveal that unlike traditional ways of improving writing skills, blogging has revolutionized EFL pedagogy and methodology (learning and teaching). Blogging-based writing practice is more participatory and interactive in that learners can dramatically improve their writing skills in terms of content, word choice, style, language mechanics and the like. The learner-blogger becomes aware that the arbiter is no longer the classroom teacher, the audience or readership. This study recommends that blogging be part of writing classes and be incorporated into school curricula. This essentially requires pedagogical consideration of the design of blogging-based writing materials.
\end{abstract}

Keywords: blogging, writing, EFL learners, learner blogger, blogs and EFL writing

\section{Introduction}

Practically speaking, before setting up writing tools for learners, it is vital to create an environment conducive to learning writing skills using a method that is both collaborative and individualized. Not only do learners better improve their writing skills through blogging practices, they can also build their self-confidence as writers and attract a wider audience. In time, students with varied interests can become famous bloggers with large audiences and can take ownership of their blogging-based writing. In addition, blogging practices play an active role in encouraging learners to experiment, take risks and foster their awareness to be private and public writers. Through blogging, learners can express their writing freely and can pool a wide range of ideas from one another when read or published. This helps them gain a stronger sense of analysis and interpretation of the topics they write about. In a classroom context, students are better equipped to use blogging as they receive more instruction before later becoming independent bloggers.

In the digital age, state-of-the-art technology serves as a productive platform for academic purposes. Impressively, digitization has successfully revolutionized the learning process. Blogging is one of the newer tools used in education. Etymologically, 'blog' is a blended term for 'web' and 'log'. Simply put, 'blog' is a web page that contains multimedia, commentaries and hyperlinks (Armstrong \& Retterer, 2008). Unlike Internet websites that feature texts and photographs uploaded by web developers, with no room for any participation and communication whatsoever, blogs provide access to students to express their writing ideas and share their writing skills online (Nepomuceno, 2011, p. 92). With many blogging practices introduced into education in the late 1990s, language learners now have a plethora of opportunities to express their ideas and share their writing and reading skills across the limitless Internet community. Blogging quickly gained popularity among language learners supported by web designers and developers (Armstrong \& Retterer, 2008). This was fast and easy because using blogging for writing purposes required little technological sophistication; in addition, blogs were available to different types of users and audiences. The rapid growth of interest in blogging is evident from the millions of people who write or read blogs. The Pew Internet and American Life Project revealed that approximately 12,000,000 Americans publish their blogs and approximately 57,000,000 read blogs (Lenhart \& Fox, 2006). In the same vein, approximately $81 \%$ of school students use the Internet for various purposes, among them blogging (DeBell \& Chapman, 2006). More interestingly, blogs are customizable; this allows users to 
modify their presentation templates, themes, pictures, designs, colors and several other options.

\subsection{Literature Review}

Blogging has recently gained considerable interest among EFL teachers and learners as a new approach to teach writing in classroom. Blogs place a special focus on learners' writing mechanics, energize them, and provide them with greater classroom writing dynamics. Blogging is an excellent way for learners to communicate with one another in a socially based context through technology (Lamonica, 2010, p. 5). Using blogs makes learners' writing more participatory and more focused on everyday language use (Penrod, 2007; Boling, 2008; Higginson, 2009; Stanley, 2013). Research studies reveal that blogs play a considerable role in improving learner reflection, classroom dialogue and social networking (Ray \& Hocutt, 2006; Khourey-Brown, 2005; Efimova \& de Moor, 2005). Blogs also enhance the writing skills of elementary, intermediate and secondary school students (Glewa \& Bogan, 2007; Lomicky \& Hossain, 2008). The aim of this research paper is to investigate the effectiveness of online blogging for students' individual and group writing skills. The paper also explores how blogs can help students to develop their writing skills in non-traditional ways, which can in turn add a great value to writing pedagogy and methodology.

What is good about using blogs in writing classes is that they introduce the use of outside school practices of literacy (Pahl \& Rowsell, 2005). According to sociocultural theory, literacy is as a socially based practice and is mediated by a person's culture (Larson \& Marsh, 2005). It can be enhanced through dialogue, discussion and storytelling. This creates self-expression and helps students discuss their ideas and then put them in writing either individually, in pairs or in a group. In this sense, blogging per se is not technology; rather, it is literacy, which underscores the strengths of authentic writing. Collaborative writing becomes a key issue at school that students should be engaged in (Boling et al., 2008). Unlike traditional methods of teaching writing skills, blogging introduces students to conversation, interaction, communication and debate before the actual writing stage. Many teachers unfortunately limit themselves to using a paper-and-pencil method to teach a writing class, but this often seems desultory (Barone \& Wright, 2008). Blogging also gives students a personal purpose that makes writing more engaging than the academic critical thinking adopted by most curricula (Boling, 2008).

Academic blogging provides a good environment for literacy processes of various kinds, such as critical thinking, reflection, questioning, modeling, social practices, discussion and development, when teachers adopt it for classroom practices (Merchant, 2005; McGrail \& Davis, 2011). Blogging also provides a space for writing down ideas in their embryonic stage to be refined later (Davies and Merchant, 2007, p. 170). When engaged in academic blogging, writers can develop and nourish their community through collaboration (Miller and Shepherd, 2004). Inasmuch as humans are born with an innate desire to learn in a social setting involving collaborative practices, literacy involves all socializing practices that begin at home and are later developed by further communication with others, and blogging is a case in point (Lamonica, 2010, p. 5).

When blogging is used in classroom, it helps learners to be active members of a community characterized by its constant changing rhythm, where knowledge is built up within a large sociocultural system (Larson \& Marsh, 2005). This makes a quantum leap in teaching writing, with a shift from traditional methods such as teacher-centered and student-centered methods to a learning-centered method. This means that optimally learning takes place through participation and collaboration in a sociocultural context mediated by instruction. For undergraduate students, blogging is a key to learning, as they share ideas, socialize, communicate, debate, discuss and better express their ideas when they see those of their classmates, and vice versa.

Upper-elementary teachers reported a lack of preparation for teaching writing (Gilbert \& Graham, 2010) due to the short 15-minutetime period. Given such time constraints, teaching metacognitive thinking skills relating to writing ideas and writing development is impossible (Kixmiller, 2004). It is also good to know one's reader and that reader's interpretation of the blogging-based writing material. This is a real challenge for students learning writing skills through blogging activities (Kellogg, 2008).At the undergraduate stage; students must take their writing ideas and their reader's possible interpretation(s) into consideration. With their readers in mind, students writing through blogging can imagine their audience's point of view and thus can revise and improve their ideas and writing style (Holliway \& McCutchen, 2004). Several blogging platforms provide students with access to a larger audience, and when blogging practices are well designed and planned, students can write about interesting ideas for longer periods of time (McGrail \& Davis, 2011, p. 417). As such, readers can also serve as a barometer of students' writing in terms of development, interest and sense (Torrance, 2007).

The paradigm shift in language learning dictates a shift from so-called teacher-centeredness to learner-centeredness in an EFL context since the 1950s (Brown, 1987). Empowered by digitization, the learning process can also now shift toward learning-centeredness, and the project-based approach has become more 
preferable among EFL teachers and learners (Özdemir \& Aydin, 2015, p. 372).

The learning environment, among other socio cultural factors, is one challenge that EFL learners and teachers face in their writing classes (Okan, 2008). A persistent problem is the lack of classrooms designed for language learning and equipped with the necessary audio-visual tools to facilitate learning language skills (Özdemir \& Aydin, 2015, p. 373). What facilitates language learning by learners' perceptions is the way instructions are delivered (Lowyck \& Clarebout, 2004). Nonetheless, students with positive attitudes toward their learning environment are more likely to write better. Crowded classrooms can negatively affect language learning (Yaman, 2009).

As practical tools, blogs create wonderful opportunities in an EFL environment both for teachers and for learners (Aydin, 2014). The use of blogging in writing classes could help students improve their writing performance when they receive well-organized instructions (Wu, 2005). In a research study conducted by Vurdien (2013), the results revealed that the use of blogs by teachers helped students improve their writing ability and write better in specific tasks. Blogs also fostered collaboration among students, and the use blogging played a positive role in understanding how the learners' feedback can be effective. A research study was conducted to examine the effects of extensive writing. The study used different stages of blog entries written by the participants sampled for the same study. The results showed that blogs could play a useful role in improving students' writing performance through motivating them and enhancing what is known as learner autonomy in boosting writing skills (Sun, 2010).

When the potential use and value of blogs in language learning was examined in Taiwan, the results revealed that there was a general acceptance of blogs by students as a productive tool to improve their language skills, such as writing, vocabulary, self-expression, socializing and thinking skills (Noytim, 2010). In the same vein, Hashemi and Najafi (2011) stated that the use of blogs has a positive impact on teaching writing skills to EFL learners. Arslan and Sahin-Kızıl (2010) observed that blog-based writing can play an important role in improving students' writing performance. Similarly, a study conducted by Koçoğlu (2009) revealed that the use of blogs was significant in terms of learners' writing and speaking skills.

\subsection{Significance of the Study}

This research study aimed to investigate the effectiveness of online blogging on students' individual and group writing skills in an EFL Saudi context. It also explored how blogs can help students to develop their writing skills in a non-traditional way, which can in turn add a great value to writing pedagogy. There is a host of reasons why this study is important. First, the results of this study will contribute to the related literature in terms of the efficiency of utilizing blogs in an EFL Saudi context for the development of undergraduates' writing skills. Second, the study motivates EFL teachers and learners to depart from their traditional pedagogical methods in favor of a digital method conducive to optimizing writing performance: blogs digitize and revolutionize writing classes. Third, the results will offer practical and helpful recommendations for teachers, learners, curriculum designers, blog designers and decision-makers in education.

\subsection{Questions of the Study}

Bearing the significance of this research study in mind, one question stands out: Does online blogging have an effect on students' individual and group writing skills in the Saudi EFL context? This study examines in particular the role of blogging in EFL writing classes and explores which microscopic writing skills can be affected among learners. It also investigates what benefits EFL teachers gain when adopting blogging in writing instructions.

\section{Method}

\subsection{Participants}

The sample group consists of 40 undergraduates in the ELT Department at a Saudi university in 2017. It was all-male because coeducation in Saudi Arabia is uncommon: male students are separated from female students in classrooms to create a better learning environment. All the participants studied English as a foreign language but did not have the same level of English-language skills. They were divided individually and in groups to see how learning through blogging could be different when used alone or in groups. The individuals were asked to write before and after being placed in groups and were examined to see how their blogging-based skills may have developed. There were 14 individual participants and 6 groups, wherein students cooperated closely to write something on a selected topic. Each group chose a name to identify them from their counterpart groups. The individual students used their own names. 


\subsection{Instruments and Procedures}

The data collection consisted of individuals and groups writing before and after the use of blogging for writing practice to examine if that use is beneficial for EFL learners. The experiment was conducted over a fourteen-week period, during which participants used online blogging for writing practice both as individuals and as groups. The students were asked to write about a topic of their choice as individuals and as groups before using the blogs. The purpose was to examine what their writing skills would be without utilizing blogging. The participants were asked again to write as individuals and as groups. To check their writing with and without the use of blogging, Writer's Choice: Writing Assessment and Evaluation Rubrics, published by Glencoe McGraw Hill (2000), was adopted as a guideline for assessment, investigation and research purposes.

\subsection{Tasks}

The study was conducted in two stages over 14 weeks with a (1) pre-test and (2) post-test, both of which have the same writing achievement test materials: a topic of their choice and the writing rubric assessing their writing performance. To draw a valid and useful comparison, the participants were asked to write their topics before and after utilizing blogs to examine how blogging can affect their writing skills in terms of writing ideas, style, mechanics of writing, socializing, discussion and other writing practices. In the pre-test, some of the participants used the traditional pen-and-paper method, while in the post-test; they used blogs to write their topics. Next, the pre-test and post-test of individual and group writing results were compared, analyzed, and assessed to examine the effect of blogging on the participants' writing performance.

\subsection{Data Collection}

The pre-writing and post-writing samples based on blogging make up the primary sources of the data in the research study, in addition to blog posts that students have made throughout the project. As mentioned earlier, students were asked to write twice: once as individuals and once as part of a group. At the same time, they were asked to do so before and after they were exposed to blogging materials. The students were exposed to a substantial sample of blogging materials to show them how their writing skills could be improved through learning microscopic skills from rich blogging materials, and this was done purposefully to investigate the difference between their improvement as individuals and as part of a group. The researcher could not videotape the sessions while the students were working in groups to observe discussions. It might be a good idea to do so and to document students' thought processes while they discuss writing among themselves via blogging and could serve as a pedagogical check for future studies (Cresswell, 2003). It should be noted that a general qualitative approach to data analysis was adopted (Merriam, 1998; Cresswell, 2003). The analysis focused on certain aspects of students' writing samples, in particular on macroscopic and microscopic writing skills, including thinking, cohesion, coherence, content, attitude and social interaction. The researcher examined the writing of the individual students and the group work to see how blogging can be instrumental in improving writing skills.

\section{Results}

The visibility of blogs in Saudi Arabia is becoming an increasingly keen area of interest among those willing to express their ideas through writing via virtual communication on social media. The availability of blogs has given many language learners a major opportunity to show robust engagement in developing their writing skills, whether by working individually or in groups. Surprisingly, enough, approximately $46 \%$ of the participants had never heard of blogging before they were asked to use blogs, while $14 \%$ had a good idea about blogging, $2 \%$ had actively contributed to blogs, and $48 \%$ showed a passive use of them: they read the blogging materials but did not participate in activities such as in writing, interaction, discussing and creating ideas. The results of the participants' sample writing revealed interesting indicators about how blogs have contributed to their macroscopic and microscopic writing skills.

\subsection{Content}

The writing by individual participants improved in terms of content. As the participants knew that their writing would be read by others, and as they had looked at blogging-based writing samples, the content was much improved: they developed their thoughts, added in-depth discussion and included rich ideas not found in their first attempts. For the groups' writing samples, it seems that the participants greatly benefited from their collective efforts in including more engaging ideas, which made their writing almost publishable. They included more ideas and approached the topic from different yet related perspectives. As they had made more attempts to see how blogging writing materials were presented, most groups improved their writing content to make it more readable, understandable and informative. By comparison, then, the group's writing content seems to have 
improved more than the individual's work through the use of blogging. However, there is room for improvement in both results. Blogging helped both individual learners and groups come up with more engaging ideas, which in turn made their writing lengthier than it had been prior to their interaction with blogging materials.

\subsection{Language Mechanics}

The use of punctuation as observed in the individual work seems to have improved only somewhat: several cases where capital letters should have been used were left unattended, and several commas and full stops passed unnoticed as well. As for grammar, mistakes in tense were observed before and after the use of blogging materials. Some individual writing samples featured mistakes in the simple present tense in certain instances, while the same sampled individuals used the simple present tense appropriately elsewhere in their writing. The group's work was much improved in terms of language mechanics, but some microscopic skills will require in-depth practice, for which blogging may not prove to be that helpful.

\subsection{Word Choice}

Individual writings in general showed good word choice before and after blogging was used to improve word choice skills. However, most did not feature any sophisticated language or words of a specific genre. It seems that appropriate word choice is a relative ability that depends on individual differences in language competence. Bernstein (2004) advocates that frequent writing improves writing in that word choice becomes immediate, with much less interference from the learner's first language. While using blogging, learners feel it is easier to verify the words they are unaware of or unsure about. This also helps them avoid first-language interference as much as possible. The group's writings seem generally better with regard to word choice. The participants here have the opportunity to replace any misused word to create a better writing flow. Blogging provides users with words that are more appropriate in terms of register and genre.

\subsection{Style}

An individual's writing is generally personal, as it reflects how one wish to express one's ideas about a specific topic of one's choice. Blogging seems to have positively affected the individual learners' writings in that their style is now more likely to be publishable. In the group's work prior to blogging, the amount of writing seemed minimal, with many ideas needing expansion. However, after using blogging the style and quantity improved: existing ideas were elaborated, and several new ones were added and fleshed out. Thus, it appears that blogging is a helpful tool that provides learners with good reading models, which in turn help them imitate or even surpass these materials written by bloggers.

The learner-bloggers, so to speak, spent quality time interacting with the blogging writings and became a receptive and motivated audience; this is the stage that precedes effective writing. In the pre-writing samples of both individuals and groups, however, prior to their interaction with blogging, ideas seemed very fragmented and disjointed, and sentences lacked coherence and cohesion.

One should note that many writings sounded as if the writer's voice was addressing a teacher or researcher and not a real or virtual audience. To some extent, this negatively affects the level or quality of writing. However, with time and much practice, the learners felt they had good access to their audience and could write for it and improve their writing, as what they wrote would be read online by someone who might offer comments and feedback. As practice time progressed, learners using blogging tried to transform their writings when they acknowledged their audience and expected or anticipated a level of interaction in the form comments, criticism or support. This required their full attention to produce better work. The participants further improved several macroscopic and microscopic writing skills through the use of blogging, as shown in Figure 1 and Figure 2. The bar graph represents the participants' writing skills with regards to content, language mechanics and use, style, word choice and self-confidence in their pre-writing and post-writing samples of blogging-based practices: 


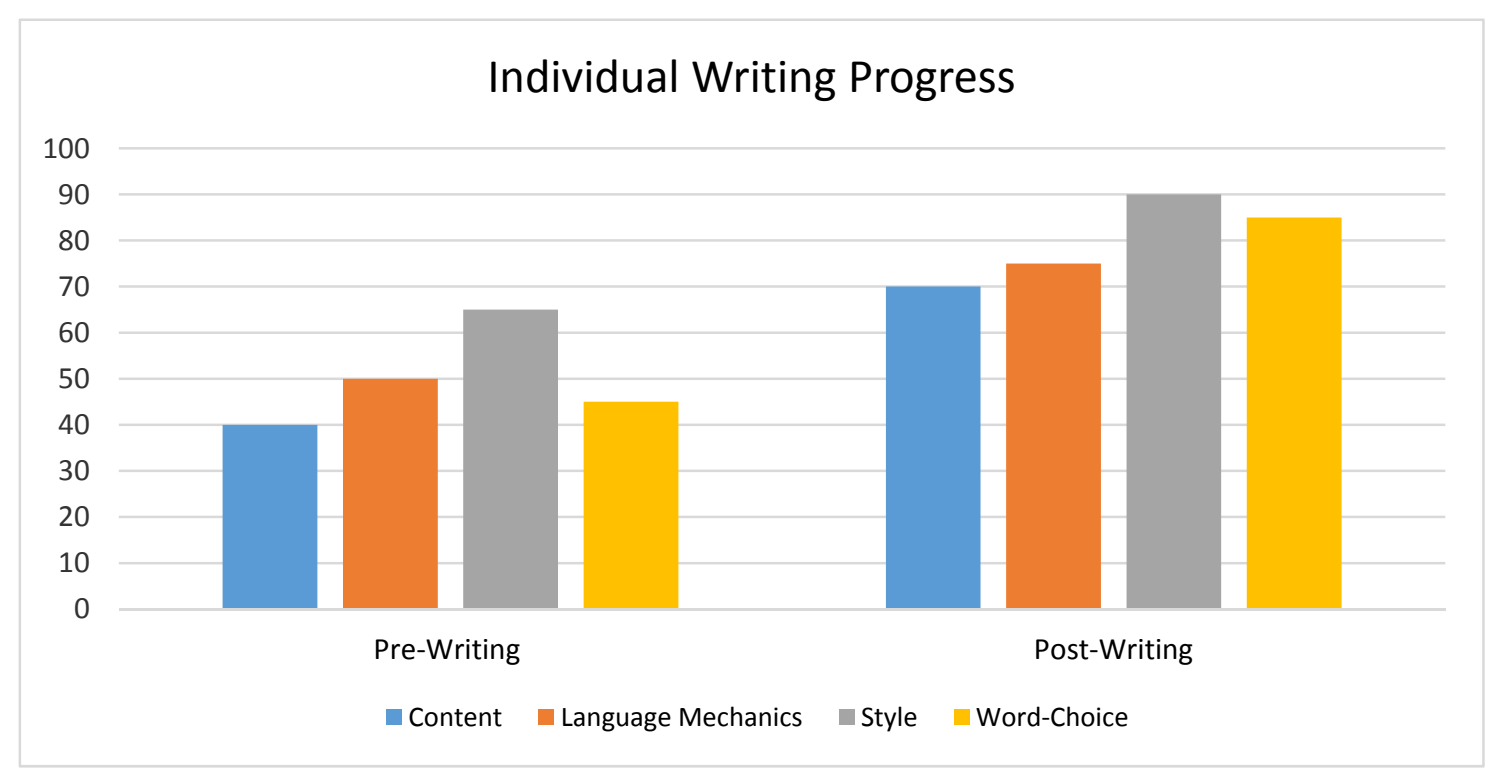

Figure 1. Individual writing progress

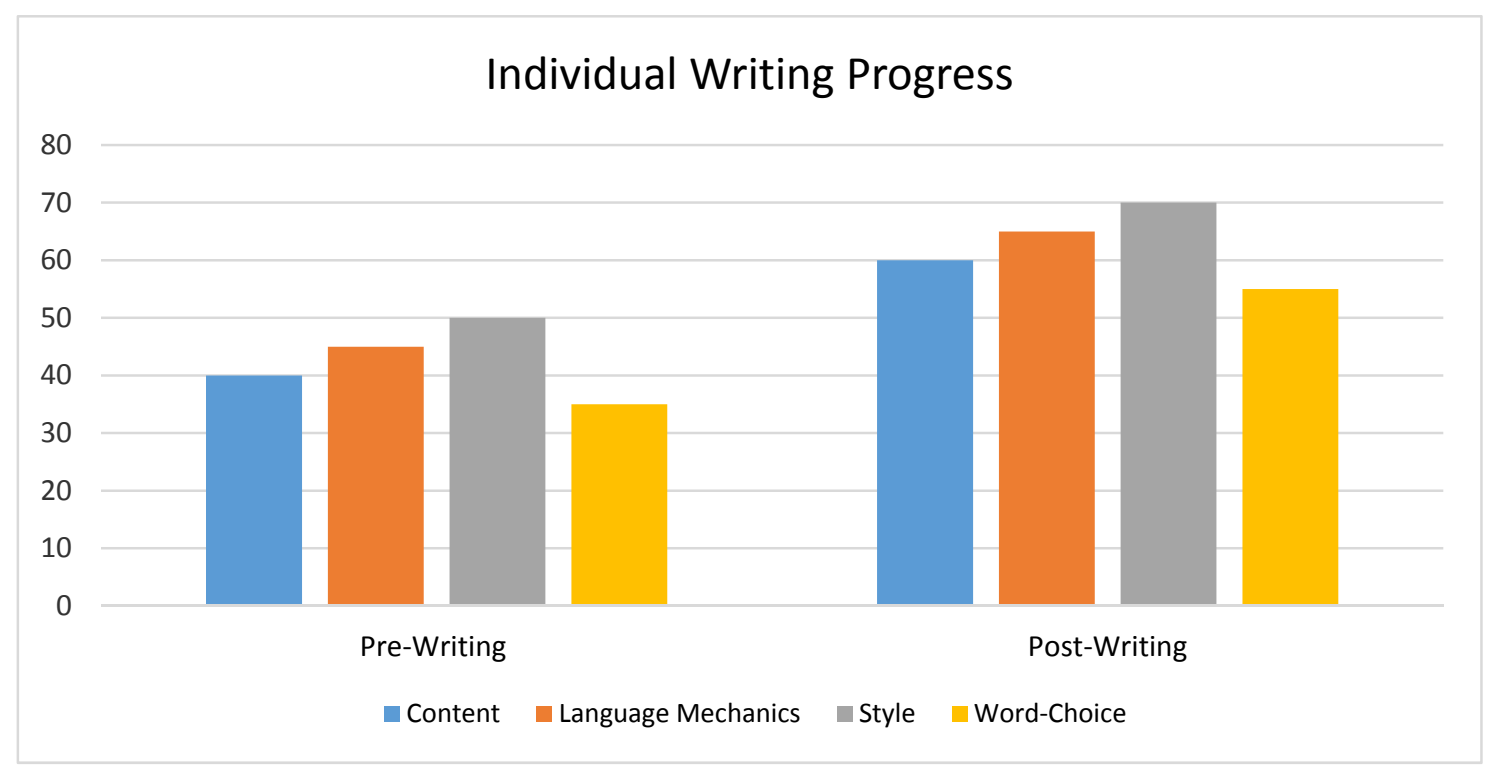

Figure 2. Group writing progress

\section{Pedagogical Implications}

In the current research study, the sample of participants, so-called learner-bloggers, developed a new understanding and appreciation of blogging-based support to improve their writing skills. Although the teacher was their primary audience at first, participants widened their audience to include bloggers interactively through discussion, comments, criticism and participation (MacArthur et al., 2005).Thus, the teacher was no longer alone in judging their writing. Blogging became a space where they could improve their writing, and where numerous readers and bloggers were also arbiters in matters of language usage and mechanics, cohesion, coherence, idea generation, debate, discussion, critical thinking, and so on (Garret, 2009). This made the learner-bloggers more ambitious, and they could now make plans to improve their literacy skills following their initial attempts. With their conception of which their audience and readership are, their writing skills developed, and they began produce more engaging work in terms of content, style, language mechanics, word choice, and so on.

In other words, the participants' awareness and understanding of their audience and readership changed dramatically, as shown in the research results: they developed a reader-friendly relationship with their blogging audience, which was no longer merely an abstract idea (Walker, 2005). They revealed that the audience and 
readers with whom they blogged were real people who shared interesting ideas, interests and passions about the selected topic. This made their writing-based discussions more engaging, in that bloggers can freely express their ideas in various voices. Of course readers play a vital role in directing and developing the participants' writings (Hartley, 2007), which makes participants' ideas, ways of thinking and writing styles more engaging.

The learner-bloggers felt encouraged to revise their writing when they realized that their work would be read interactively by their audience and readers. This makes writing content more effective and convincing (Mortensen \& Walker, 2002). Another benefit that participants gained from using blogging to improve their writing skills is that blogging per se allows participants to discuss their ideas in a public forum, as opposed to the traditional writer-reader relationship, which produces printed materials such as books, articles, plays and novels (Merchant, 2008). Now, with the assistance of blogging to improve learners' writing skills, the participants developed their sense of writing in a readerly and writerly fashion (Swenson et al., 2006). When practiced as such, blogging also motivates and empowers participants to enhance their authorial skills.

The researcher who assumed the role of blogging teacher managed to optimize and orchestrate the participants' interactions with their writing materials. Blogging technology opened the doors wide for them to go beyond traditional ways of writing to their teacher, who in this case is the only reader. This helps the teacher in fostering participants' desire to become more influential writers and to self-correct their language through increasingly interactive writing productions. Participants also became motivated learners, acting as representatives of their own ideas, and this helped to inform, change and reshape their writing practices through blogging (Schneider \& Evans, 2008). It also created self-confidence among participants and a desire to share their ideas about a wide range of topics willingly.

\section{Conclusion}

Blogging is a user-friendly platform that helps EFL teachers and learners to improve many of their writing skills. Generally, participants showed noticeable improvement in several writing components, such as content development, language mechanics, style, voice, word choice and other writing sub-skills. With the teacher operating through a well-organized instructional design in the classroom or in a virtual platform, a blog is definitely a good starting point for EFL teachers to make EFL learners depart from traditional methods of writing in favor of a much more interactive, writerly and readerly approach.

The results also revealed that working in a group more than working as individuals helped improve writing skills. This is due to the discussions that group members may have had while blogging. Moreover, when the learners realize that their readers and audience is no longer their teacher(s) only, they become more aware of paying particular attention to what they write and to revise it, probably many times, to ensure the final product is more interesting in terms of both content and form. This continued interaction catalyzes the learners' desire to keep writing and communicating in a two-way fashion: with the reader and with themselves.

It is therefore recommended to utilize blogging in such a way that facilitates EFL learners' writing classes and improves their macroscopic and microscopic writing skills. The results also revealed that learners must read more about how to blog and how to interact with 'the other side'; this helps them to discover ways to share ideas and improve their writing styles and preferences. Blogging is a social platform for writing practices, and it is a language (EFL) platform for self-learning and self-teaching in a holistic and, in many cases, heuristic fashion. As writing is a skill based on blogging, EFL learners must be good readers to better write about a variety of topics, as their readers may be remarkably interactive and keen to respond to their ideas.

\section{References}

Applebee, A., \& Langer, J. (2009). What is happening in the teaching of writing? English Journal, 98(5), 18-28.

Boling, E. (2008). Learning from teachers' conceptions of technology integration: What do blogs, instant messages, and 3D chat rooms have to do with it? Research in the Teaching of English, 43(1), 74-100.

Creswell, J. W. (2003). Research design: Qualitative, quantitative, and mixed methods approaches (2nd Ed.). Thousand Oaks, CA: Sage.

Davies, J., \& Merchant, G. (2007). Looking from the inside out: Academic blogging as new literacy. In C. Lankshear, \& M. Knobel (Eds.), A new literacies sampler (pp. 167-197). New York, NY: Peter Lang.

Davis, A., \& McGrail, E. (2009). The joy of blogging. Educational Leadership, 66(6), 74-77.

Garret, J. (2009). Resources for teaching writing. The California State University.

Hartley, J. (2007). Digital literacy and the active audience: Growing objective knowledge and creative imagination in post-broadcast media. In Proceedings of the Transforming Audiences Conference (pp. 1-12). 
London, England.

Herrington, A., Hodgson, K., \& Moran, C. (2009). Challenges for writing teachers. In A. Herrington, K. Hodgson, \& C. Moran (Eds.), Teaching the new writing: Technology, change, and assessment in the 21st-century classroom (pp. 1-17). New York, NY: Teachers College Press.

Higginson, S. (2009). A Case Study on the Impact of Weblogs on the Writing of Low-Level Learners in the University of Chile. Florida: Universal-Publishers.

Huffaker, D. (2005). The educated blogger: Using weblogs to promote literacy in the classroom. AACE Journal, 13(2), 91-98.

Kellogg, R. T. (2008). Training writing skills: A cognitive developmental perspective. Journal of Writing Research, 1(1), 1-26. https://doi.org/10.17239/jowr-2008.01.01.1

MacArthur, C. A., Graham, S., \& Fitzgerald, J. (Eds.). (2005). Handbook of writing research. New York, NY: Guilford Press.

Merriam, S. B. (1998). Qualitative research and case study applications in education. San Francisco, CA: Jossey-Bass.

Mortensen, T., \& Walker, J. (2002). Blogging thoughts: Personal publication as an online research tool. In A. Morrison (Ed.), Researching ICTs in context (pp. 249-279). Oslo, Norway: InterMedia, University of Oslo.

Nepomuceno, M. (2011). Writing Online: Using Blogs as an Alternative Writing Activity in Tertiary ESL Classes. TESOL Journal, 5, 92-105.

Özdemir, E., \& Aydin, S. (2015). The Effects of Blogging on EFL Writing Achievement. Procedia - Social and Behavioural Sciences, 199, 372-380. https://doi.org/10.1016/j.sbspro.2015.07.521

Penrod, D. (2007). Using blogs to enhance literacy: The next 21st-centruy learning. Lanham, MD: Rowman \& Littlefield Education Publishers.

Schneider, S. B., \& Evans, M. A. (2008). Transforming e-learning into e-learning: The centrality of sociocultural participation. Innovate, 5(1).

Stanley, G. (2013). Language Learning with Technology: Ideas for Integrating Technology in the Classroom. UK: Cambridge University Press.

Swenson, J., Young, C. A., McGrail, W., Rozema, R., \& Whitin, P. (2006). Extending the conversation: New technologies, new literacies, and English education. English Education, 38(4), 349-367.

Walker, J. (2005). Weblogs: Learning in public. On the Horizon, 13(2), 112-118. https://doi.org/10.1108/10748120510608142

\section{Copyrights}

Copyright for this article is retained by the author(s), with first publication rights granted to the journal.

This is an open-access article distributed under the terms and conditions of the Creative Commons Attribution license (http://creativecommons.org/licenses/by/4.0/). 